\title{
Maternal Mortality in Ghana: Impact of the Fee-Free Delivery Policy and the National Health Insurance Scheme
}

\author{
Seidu Sofo ${ }^{1}$, Emmanuel Thompson ${ }^{2}$ \\ ${ }^{1}$ Department of Health, Human Performance \& Recreation, Southeast Missouri State University, USA \\ ${ }^{2}$ Department of Mathematics, Southeast Missouri State University, USA
}

\begin{tabular}{l} 
Article Info \\
\hline Article history: \\
Received Aug 2, 2015 \\
Revised Aug 25, 2015 \\
Accepted Aug 30, 2015 \\
\hline Keyword: \\
Ghana \\
Maternal mortality \\
Millennium development goal \\
Panel data model \\
Skilled delivery
\end{tabular}

\section{Corresponding Author:}

Seidu Sofo,

Department of Health, Human Performance \& Recreation,

Southeast Missouri State University,

1 University Plaza, Cape Girardeau, MO 63701, USA.

Email: ssofo@semo.edu

\begin{abstract}
Maternal mortality (MMR) is the second largest cause of female deaths in Ghana. Yet, many households cannot afford the cost of skilled delivery The study utilized the Panel Data Model to examine the impact of the fee-free delivery (FEP) and the National Health Insurance Policy (NIP) exemptions on MMR in Ghana. The Demographic and Health Survey reports on Ghana from 2002 to 2009 served as the main data source. Data were analyzed using Panel data model with within group fixed effects estimator.MMR declined significantly over the period studied. Both FEP and NIP positively impacted MMR at a 5\% level of significance.In addition, skilled delivery was a significant predictor of MMR. Stakeholders would do well to ensure that NIP is adequately funded in order to sustain the decline in MMR.
\end{abstract}

Copyright (c) 2015 Institute of Advanced Engineering and Science. All rights reserved.

\section{INTRODUCTION}

Despite the decline in maternal mortality ratio (MMR) globally, it is likely that Ghana (as other African countries) will not attain the Millennium Development Goal 5 by the year 2015 [1]. Maternal mortality, which accounts for $14 \%$ of all female deaths, is still the second largest cause of female deaths in Ghana [2]. A major factor in reducing MMR is the availability of skilled delivery [3]. For example, [4] reported skilled delivery as the factor that most predicted MMR in Ghana. However, many households in sub-Saharan Africa cannot afford the cost of skilled delivery, especially emergency obstetric care [5],[6].

To increase accessibility to skilled delivery, Ghana introduced a fee-free delivery policy (FEP) in four regions of the country in 2003: Northern, Upper East, Upper West, and Central regions [7]. The policy provided free delivery services at all public and private health facilities. The fee exemption was extended to the rest of the country in 2005. The exemption covered all normal deliveries, management of all assisted deliveries, and management of medical and surgical complications arising out of deliveries [7].

The fee exemption policy resulted in increase in facility delivery coverage [8]-[10] the increase was greatest among the poorest. On a positive note, the quality of care did not deteriorate due to increased utilization without a corresponding increase in resources [11]. Second, there was a significant drop in out-ofpocket payments for caesarean section and normal delivery after introduction of the policy, especially among the poorest [12]. Third, delivery-related MMR in two regions decreased, even though these were not statistically significant [8]. Finally, the policy resulted in a decline in direct maternal deaths but not on indirect maternal deaths [13].

A major challenge for the fee-free delivery policy was that doctors were not well prepared to deal with the obstetric conditions commonly seen in district hospitals [10]. In addition, some regions had 
exhausted funds by late 2005 [5]. The lack of funds resulted in a decline in facility deliveries between 2006 and 2007 [12]. To address this setback, the government in 2008 exempted pregnant women from paying the National Health Insurance Scheme (NHIS) registration and premium fees. The 2008 policy provided pregnant women with six antenatal and two postnatal visits, childcare and other primary healthcare benefits [8]. There is evidence to support the positive impact of health insurance on maternal health [14]. However, little is known about the impact of both the fee-free delivery and health insurance fee exemption policies on MMR nationwide.

To date, studies on the FEP and NIP policies focused on healthcare utilization and economic outcomes, and were conducted in a few selected regions of the country. Furthermore, the few studies that examined the effect of these policies on MMR reported mixed results [8],[13]. Therefore, the aim of the current study was to examine the impact of the fee-free delivery and the NIP exemptions on MMR in Ghana. The specific objectives were to examine: (a) if there was significant decline in MMR post policies and (b) the significant predictors of MMR after implementation of the policies.

\section{RESEARCH METHOD}

The Demographic and Health Survey data for Ghana from 2002 to 2009 [15] served as the main data sources. The variables used from the surveys included: MMR (response variable), Doctor Population Ratio (DR), Nurse Population Ratio (NR), Antenatal Coverage (ANC), Postnatal Coverage (PNC), Skilled Delivery (SD), and Family Planning Acceptors (FPA). MMR values for the periods before and after the introduction of the FEP and NIP were compared to determine the impact of the policies.

Data were analyzed using descriptive and inferential statistics. Averages, standard deviations, coefficients of Skewness and Kurtosis, and confidence intervals were computed for the introduction of FEP (2002-2005), impact of FEP (2006-2008), and impact of NIP (2009). The study utilized the within group estimator to analyze the impact of two health insurance policies in Ghana. These policies included FEP and NIP. The FE estimator is appropriate for panel data- data collected on the same subjects over time. Panel data are correlated within subjects but independent between subjects. This is a characteristic that the data in the current study exhibit, hence the choice of within group fixed effects estimator. To introduce the within group fixed effects estimator, we first provide a brief description of panel data model.

\subsection{Panel Data Model}

A Panel data model with one-way error components disturbances is given by

$$
y_{i t}=x_{i t}^{\prime} \beta+\mu_{i}+\vartheta_{i t} \quad i=1, \ldots, N ; t=1, \ldots, T
$$

The $\mathrm{i}$ and $\mathrm{t}$ denote the cross-section and time-series dimensions respectively. $\beta \mathrm{isK} \times 1$ and $\mathrm{x}_{\mathrm{it}}$ is the it ${ }^{\text {th }}$ observation on $\mathrm{K}$ predictor variable. $\mu_{\mathrm{i}}$ is the unobserved heterogeneity across individuals that is fixed over time. $\vartheta_{\text {it }}$ denotes the stochastic term which is independent, identically distributed (i.i.d.) with mean 0 and variance $\sigma_{\vartheta}^{2}$.

\subsection{Within Group Fixed Effects Estimator}

To implement the within group estimator, we consider (1) and then assume that $\mathrm{E}\left(\mathrm{X}_{\mathrm{it}} \mu_{\mathrm{i}}\right) \neq 0$, $\mathrm{E}\left(\mathrm{X}_{\mathrm{it}} \vartheta_{\mathrm{it}}\right)=0$, and $\mathrm{E}\left(\vartheta_{\mathrm{i}} \vartheta_{\mathrm{i}}^{\prime}\right)=\Sigma$. Stacking all the observation for $\mathrm{t}=1, \ldots, \mathrm{T}$ as presented in [16] we obtain

$$
\underset{\mathrm{T} \times 1}{\mathrm{y}_{\mathrm{i}}}=\underset{(\mathrm{T} \times \mathrm{M}) \underset{(\mathrm{M} \times 1)}{\mathrm{x}_{\mathrm{i}}} \stackrel{\beta}{\beta} \underset{(1 \times 1)}{\mu_{\mathrm{i}}} \underset{\mathrm{T} \times 1)}{1} 1_{\mathrm{T}}}{\stackrel{\vartheta_{\mathrm{T}} \times 1}{\vartheta_{\mathrm{i}}}}
$$

Let

$$
\underset{\mathrm{T} \times \mathrm{T}}{\mathrm{V}_{\mathrm{T}}}=\mathrm{I}_{\mathrm{T}}-1_{\mathrm{T}}\left(1_{\mathrm{T}}^{\prime} 1_{\mathrm{T}}\right)^{-1} 1_{\mathrm{T}}^{\prime}=\mathrm{I}_{\mathrm{T}}-\mathrm{U}_{\mathrm{T}}
$$

and

$$
\mathrm{U}_{\mathrm{T}}=1_{\mathrm{T}}\left(1_{\mathrm{T}}^{\prime} 1_{\mathrm{T}}\right)^{-1} 1_{\mathrm{T}}^{\prime}=\mathrm{T}^{-1} 1_{\mathrm{T}} 1_{\mathrm{T}}^{\prime}
$$

Note the following:

i. $\mathrm{U}_{\mathrm{T}} 1_{\mathrm{T}}=1_{\mathrm{T}}$

ii. $\mathrm{V}_{\mathrm{T}} 1_{\mathrm{T}}=0$ 
iii. $\mathrm{U}_{\mathrm{T}} \mathrm{y}_{\mathrm{i}}=1_{\mathrm{T}}\left(1_{\mathrm{T}}^{\prime} 1_{\mathrm{T}}\right)^{-1} 1_{\mathrm{T}}^{\prime} \mathrm{y}_{\mathrm{i}}=1_{\mathrm{T}}^{\prime} \overline{\mathrm{y}}_{\mathrm{i}}$

iv. $\mathrm{V}_{\mathrm{T}} \mathrm{y}_{\mathrm{i}}=\left(\mathrm{I}_{\mathrm{T}}-\mathrm{U}_{\mathrm{T}}\right) \mathrm{y}_{\mathrm{i}}=\mathrm{y}_{\mathrm{i}}-1_{\mathrm{T}} \overline{\mathrm{y}}_{\mathrm{i}}=\overline{\mathrm{y}}_{\mathrm{i}}$

From the above, we obtained a transformed form of (2):

$\mathrm{V}_{\mathrm{T}} \mathrm{y}_{\mathrm{i}}=\mathrm{V}_{\mathrm{T}} \mathrm{X}_{\mathrm{i}} \beta+\mu_{\mathrm{i}} \mathrm{V}_{\mathrm{T}} 1_{\mathrm{T}}+\mathrm{V}_{\mathrm{T}} \vartheta_{\mathrm{i}}$

The regression model stacked by observation becomes:

$$
\left[\begin{array}{c}
\bar{y}_{1} \\
\vdots \\
\bar{y}_{n}
\end{array}\right]=\left[\begin{array}{c}
\bar{x}_{1} \\
\vdots \\
\bar{x}_{n}
\end{array}\right] \beta+\left[\begin{array}{c}
\bar{\vartheta}_{1} \\
\vdots \\
\bar{\vartheta}_{n}
\end{array}\right]
$$

and the within group fixed effects estimator is obtained as follows:

$$
\hat{\beta}=\left(\sum_{\mathrm{i}=1}^{\mathrm{n}}\left(\mathrm{V}_{\mathrm{T}} \mathrm{X}_{\mathrm{i}}\right)^{\prime} \mathrm{V}_{\mathrm{T}} \mathrm{X}_{\mathrm{i}}\right)^{-1} \sum_{\mathrm{i}=1}^{\mathrm{n}}\left(\mathrm{V}_{\mathrm{T}} \mathrm{X}_{\mathrm{i}}\right)^{\prime} \mathrm{V}_{\mathrm{T}} \mathrm{y}_{\mathrm{i}}
$$

However, $\mathrm{V}_{\mathrm{T}}$ is idempotent, hence $\hat{\beta}$ and the corresponding variance (Baltaji (2005)) become

$$
\widehat{\beta}=\left(\sum_{\mathrm{i}=1}^{\mathrm{n}} \mathrm{X}_{\mathrm{i}}^{\prime} \mathrm{V}_{\mathrm{T}} \mathrm{X}_{\mathrm{i}}\right)^{-1} \sum_{\mathrm{i}=1}^{\mathrm{n}} \mathrm{X}_{\mathrm{i}}^{\prime} \mathrm{V}_{\mathrm{T}} \mathrm{y}_{\mathrm{i}}
$$

and

$$
\operatorname{var}(\widehat{\beta})=\sigma_{\vartheta}^{2}\left(\sum_{\mathrm{i}=1}^{\mathrm{n}} \mathrm{X}_{\mathrm{i}}^{\prime} \mathrm{V}_{\mathrm{T}} \mathrm{X}_{\mathrm{i}}\right)^{-1}
$$

We direct readers to [16]-[18] for details on panel data models.

\section{RESULTS AND ANALYSIS}

\subsection{Trend of MMR}

Table 1 provides the descriptive statistics for MMR by period. The average MMR rose from 220.27 in 2002-2005 to 202.56 in 2006-2008 and later dropped to 171 in 2009. Also, it is very indicative from the Table 1 that, the ratio in the three different periods were not significantly skewed since the coefficients of Skewness were neither smaller than -1 nor bigger than +1 . Similarly, none of the values of the kurtosis for the ratio in the three periods were less than -3 or bigger than +3 . Hence the ratio for the three periods were not significantly heavy tailed. The $95 \%$ confidence intervals for the average MMR in the population in 20022005, 2006-2008, and 2009 were (181.34, 219.80), (183.10, 222.02), and 142.76, 199.24) respectively as shown in Table1.

Table 1. Summary Statistics of MMR in Ghana for 2002-2005, 2006-2008, and 2009

\begin{tabular}{cccc}
\hline Variable & \multicolumn{3}{c}{ Period } \\
\cline { 2 - 4 } & 2002-2005 (Intro. FEP) & 2006-2008 (Impact FEP) & 2009 (Impact of NIP) \\
\hline Average & 200.57 & 202.56 & 171 \\
Standard Deviation & 62.05 & 54.39 & 45.55 \\
Skewness & 0.59 & 0.29 & 0.82 \\
Kurtosis & 0.43 & -0.37 & -0.73 \\
95\% CI for the Mean of MMR & $(181.34,219.80)$ & $(183.10,222.02)$ & $(142.76,199.24)$ \\
\hline
\end{tabular}

The distributions of MMR for the three periods are shown in Figure 1. MMR were more spread out in 2002-2005, followed by 2006-2008, and then 2009 as indicated by the upper whiskers of the boxplots. 
These confirm that the standard deviation for MMR decreased monotonically from 2002-2005 to 2009 (see Table 1). The general trend in the boxplots indicated that MMR declinedduring the periods under observation (see Figure 1). It is important to mention thatFigure 1 shows potential outliers in the MMR data set for the periods 2002-2005 and 2006-2008.

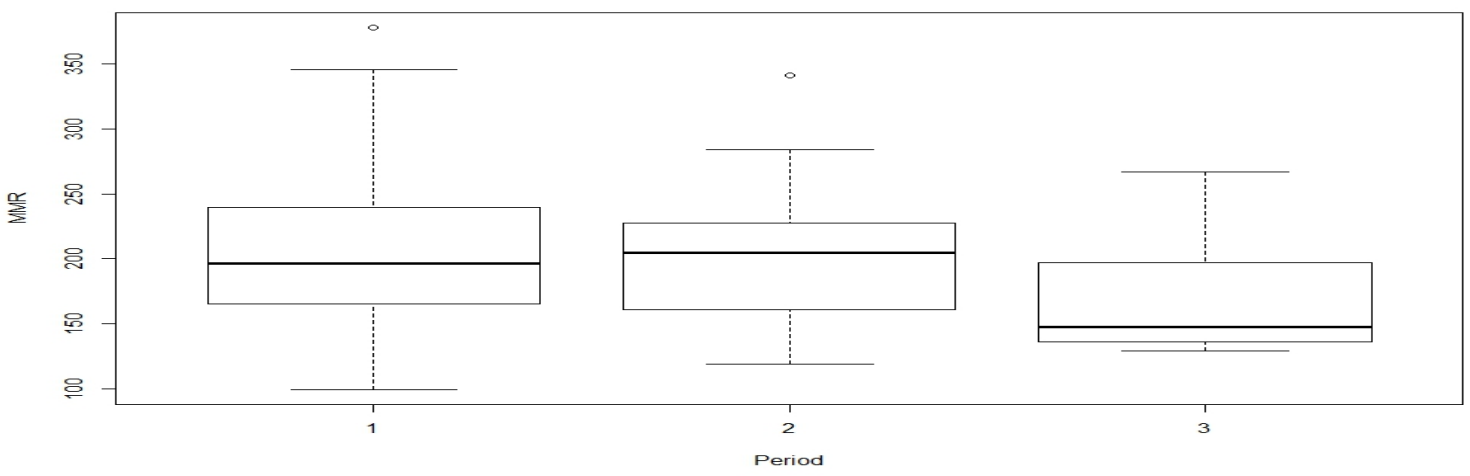

Figure 1. Distribution of MMR in Ghanafor 2002-2005, 2006-2008, and 2009

\subsection{Post Policy Effects}

Table 2 displays the estimated parameters with their corresponding standard errors, t-values and pvalues. The estimated parameters were obtained by using the within fixed effects estimator. Data in Table 2 indicate that both FEP and NIP were found to be statistically significant in predicting MMR when the level of significance was set at 5\%. For instance, MMR dropped significantly by 45.22 ( $\mathrm{t}=-2.456$, p-value $<5 \%$ ) after the introduction of FEP. Similarly, MMR decreased markedly by $51.43(\mathrm{t}=-2.369$, $\mathrm{p}$-value $<5 \%)$ after the introduction of NIP. In addition, Table 2 shows that SD was a significant predictor of MMR, while DR, NR, ANC, PNC, and FPA were not.

Table 2. Estimated coefficents for predictors of MMR in Ghana for 2002-2005, 2006-2008, and 2009

\begin{tabular}{ccccc}
\hline & Coefficient & Standard Error & t-Value & P-Value \\
\hline DR & 0.001 & 0.001 & 0.499 & .619 \\
NR & 0.004 & 0.021 & 0.206 & .838 \\
ANC & -1.280 & 1.135 & -1.127 & .264 \\
PNC & -0.079 & 0.887 & -0.089 & .929 \\
SD & -3.430 & 0.688 & -4.984 & $.000^{* * *}$ \\
FPA & 0.219 & 0.725 & 0.302 & 0.764 \\
FEP (Post Policy Effect) & -45.215 & 18.409 & -2.456 & $.017^{* *}$ \\
NIP(Post Policy Effect) & -51.425 & 21.708 & -2.369 & $.021^{* *}$ \\
\hline
\end{tabular}

\section{DISCUSSION AND CONCLUSION}

The finding of the present study that the FEP resulted in a significant decline in MMR is consistent with that of [9] even though the latter was not statistically significant.Specifically, [9] reported that deliveryrelated MMR in two regions of the country decreased after the introduction of FEP. Cross et al. [13] also reported a decline in direct maternal deaths post FEP.

Data in the present study indicated that the NIP had a significant impact on MMR-MMR declined after the introduction of the policy. This supports the assertion that health insurance coverage positively impacts maternal health [14].

Another finding of the current study was that supervised delivery was a significant predictor of MMR after the introduction of both the FEP and NIP. This finding is consistent with previous studies [4],[19] that reported the role of skilled delivery in reducing MMR. As [20] noted, stakeholders in the Ghanaian health sector need to mitigate the social factors that prevent many expecting mothers from seeking skilled delivery.

The study utilized Panel Data to investigate theimpact of the fee-free delivery and the national health insurance policy exemptions on maternal mortality ratio in Ghana.The introductions of both the FEP 
and NIP resulted in significant decline in MMR.The present study utilized data the national level;future research should investigate the effects of FEP and NIP on MMR in the regions.

\section{REFERENCES}

[1] United Nations, “Millennium development goals: 2013 report”, New York, United Nations, 2013.

[2] Asamoah, B. O., Moussa, K. M., Stafström, M., Musinguzi, G., "Distribution of causes of maternal mortality among different socio-demographic groups in Ghana: A descriptive study”, BMC Public Health, vol/issue: 11(159), 2011, doi: 10.1186/1471-2458-11-159.

[3] Campbell, O. M. R., Graham, W. J., “Strategies for reducing maternal mortality: Getting on with what works”, The Lancet, vol. 368, pp.1284-1299, 2006.

[4] Thompson, E., Sofo, S., "Maternal mortality in Ghana: An econometric analysis", Journal of Statistical and Econometric Methods, vol/issue: 3(2), pp. 115-124, 2014.

[5] Witter, S., Arhinful, D. K., Kusi, A., Zakaria-Akoto, S., "The experience of Ghana in implementing a user free exemption policy to provide free delivery care”, Reproductive Health Matters, vol/issue: 15(30), pp. 61-71, 2007.

[6] Yates, R., "Universal health care and the removal of user fees", The Lancet, vol. 373, pp. 2078-2081, 2009.

[7] Ministry of Health, “Guidelines for implementing the exemption policy on maternal deliveries”, Accra: Ministry of Health, 2004.

[8] Dzakpasu, S., Soremekun, S., Manu A., ten Asbroek, G., Tawiah, C., et al., "Impact of free delivery care on health facility delivery and insurance coverage in Ghana’s BrongAhafo Region”, PLoS ONE, vol/issue: 7(11), pp. e49430, 2012. doi:10.1371/journal.pone.0049430.

[9] Bosu, W. K., Bell, J. S., Armar-Klemesu, M., Ansong-Tornui, J., "Effect of delivery care user fee exemption policy on institutional maternal deaths in the Central and Volta regions of Ghana”, Ghana Medical Journal, vol/issue: 41(3), pp. 118-124, 2007.

[10] Penfold, S., Harrison, E., Bell, J., Fitzmaurice, A., "Evaluation of the delivery fee exemption policy in Ghana: Population estimates of changes in delivery service utilization in two regions", Ghana Medical Journal, vol/issue: 41(3), pp. 100-109, 2007.

[11] Ansong-Tornui, J., Armar-Klemesu, M., Arhinful, D., Penfold, S., Hussein, J., "Hospital based maternity care in Ghana - Findings of a confidential enquiry into maternal deaths”, Ghana Medical Journal, vol/issue: 41(3), pp. 125-132, 2007.

[12] Asante, F. A., Chikwama, C., Daniels, A., Armar-Klemesu, M., "Evaluating the economic outcomes of the policy of fee exemption for maternal delivery care in Ghana”, Ghana Medical Journal, vol/issue: 41(3), pp. 110-117, 2007.

[13] Cross, S., Bell, J. S., Graham, W. J., "What you count is what you target: The implications of maternal death classification for tracking progress towards reducing maternal mortality in developing countries", Bulletin of the World Health Organization, vol/issue: 88(2), pp. 147-153, 2010.

[14] Wang, W., Temsah, G., Mallick, L., "Health insurance coverage and its impact on maternal health utilization in low- and middle-income countries”, DHS Analytical Studies No. 45, ICF Interantional, Rockvill, MD, USA, 2014.

[15] Ghana Health Service, “The health sector in Ghana: Facts and figures 2010”, Accra, Ghana: Ghana Health Service, 2010.

[16] Zivot E., "Fixed effects estimation of paned data”, Pamphlet, University of Washington, USA, 2012.

[17] Baltagi, B. H., "Econometric analysis of panel data”, John Wiley \& Sons, Inc., New York, 2005.

[18] Elhorst, J. P., "Spatial econometrics: From cross-sectional data to spatial panels”, Springer: Berlin, New York, Dordrecht, London, 2014.

[19] Graham, W. J., Bell, J. S., Bullough, C. H. W., "Can skilled attendance at delivery reduce maternal mortality in developing countries?”, Safe motherhood strategies: a review of the evidence, vol. 17, pp. 97-130, 2001.

[20] Sappor, M., Esena, R. K., 'Utilization of skilled delivery services in Ghana: Quality improvement issues in maternal health”, International Journal of Innovative Research and Studies, vol/issue: 2(5), pp. 353-367, 2013.

\section{BIOGRAPHIES OF AUTHORS}

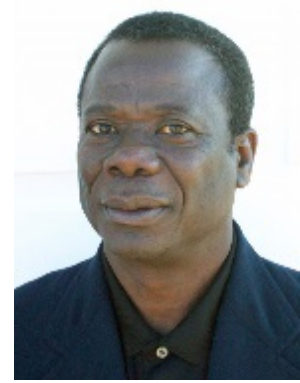

Dr. Sofo is currently a full Professor of Physical Education Teacher Education in the Department of Health, Human Performance and Recreation at Southeast Missouri State University, Missouri, USA. He holds a Ph.D. in Human Performance Studies with a concentration in Physical Education Pedagogy from The University of Alabama, USA. He obtained a MS.Ed. (Physical Education Pedagogy) from the State University of New York College at Brockport, NY. Prior to that, he graduated from the University of Cape Coast, Ghana, with a B.Ed. in Physical Education, and a Diploma in Biology. Professor Sofo has published and presented numerous peer reviewed papers at the national and international levels on: physical education teacher education, children's physical activity, perceptual-motor development, and postcolonial pedagogy. 


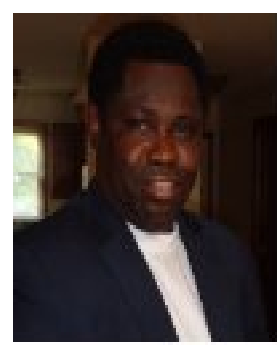

Emmanuel Thompson is an Assistant Professor of Statistics/Actuarial Science in the Department of Mathematics at Southeast Missouri State University, Missouri, USA. He is a Graduate Statistician member of the American Statistical Association and also an Affiliate member of the Institute and Faculty of Actuaries in the United Kingdom. Emmanuel holds a Ph.D. in Statistics (Actuarial Science option) and a MSc. in Actuarial Science both from University of Calgary in Canada. He also graduated from University of Cape Coast in Ghana, with a BSc. (First Class) in Statistics and has spent over six years working in the insurance industry in Ghana and briefly in Canada. Emmanuel's research agenda covers the areas of risk theory \& actuarial modeling, applied statistics, and applied econometrics. Emmanuel has published and presented different peer reviewed papers in Applied Statistics and Actuarial Science at the national and international levels. 